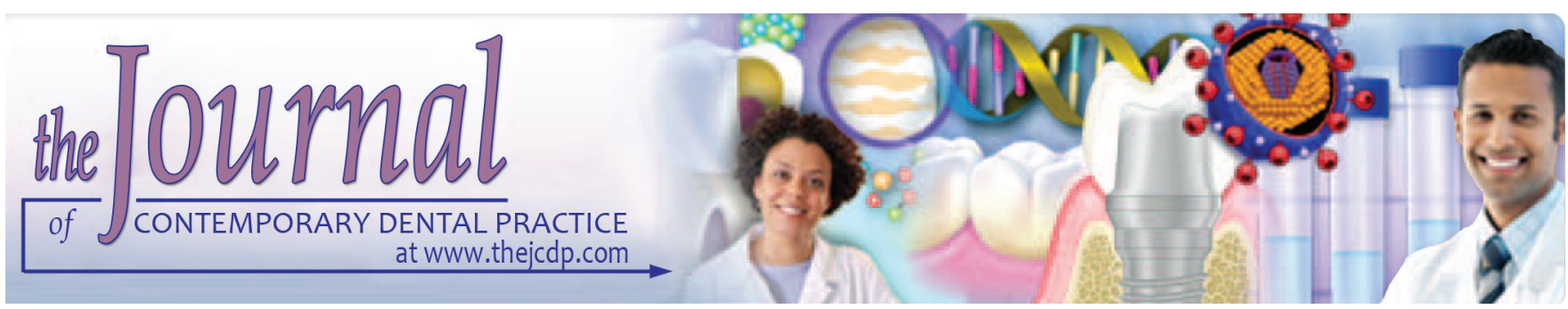

\title{
Evaluation of Mineral Trioxide Aggregate, Resin-modified Glass Ionomer Cements, and Composite as a Coronal Barrier: An in vitro Microbiological Study
}

${ }^{1}$ Nagaraj Rashmi, ${ }^{2}$ Sachin V Shinde, ${ }^{3}$ Ahmed A Moiz, ${ }^{4}$ Tarun Vyas, ${ }^{5}$ Junaid A Shaik, ${ }^{6}$ Guneet Guram

\section{ABSTRACT}

Aim: The purpose of the study is to evaluate the bacterial microleakage of three different materials, mineral trioxide aggregate (MTA), resin-modified glass ionomer cement (RMGIC), and flowable composite, as a coronal barrier against Enterococcus faecalis.

Materials and methods: A total of 100 human extracted singlerooted teeth were selected. Access opening done, working length determined, and canals were cleaned and shaped with ProTaper F3 and obturated with AH26 and gutta-percha (GP) using lateral condensation technique. Samples were divided into three experimental and two control groups. Approximately $3 \mathrm{~mm}$ GP was removed from the coronal orifice and restored with one of the test materials. Teeth were suspended in glass tubes containing brain heart infusion $(\mathrm{BHI})$ broth and equipped with microcaps, which were used to check bacterial leakage. A 24-hour broth of $E$. faecalis was placed in the pulp chamber. Tubes were incubated and checked for turbidity for 90 days. Data were analyzed using chi-squared test between the test and control groups and Fisher test between the test groups.

Results: Significantly lesser number of samples turned turbid in the RMGIC group followed by MTA group and the maximum

\footnotetext{
${ }^{1}$ Department of Conservative Dentistry, Sri Venkateshwara Dental College and Hospital, Bengaluru, Karnataka, India

${ }^{2}$ Department of Orthodontics, D.Y. Patil Hospital \& Research Centre, Kolhapur, Maharashtra, India

${ }^{3}$ Department of Conservative Dentistry \& Endodontics, Sri Sai College of Dental Surgery, Vikarabad, Telangana, India

${ }^{4}$ Department of Oral Medicine and Radiology, R R Dental College \& Hospital, Udaipur, Rajasthan, India

${ }^{5,6}$ Department of Orthodontics, Adesh Institute of Dental Sciences and Research, Bathinda, Punjab, India

Corresponding Author: Nagaraj Rashmi, Department of Conservative Dentistry, Sri Venkateshwara Dental College and Hospital, Bengaluru, Karnataka, India, Phone: +919501544877 e-mail: drrashmin@gmail.com
}

number of samples turned turbid in the flowable composite group.

Conclusion: The RMGIC is a better coronal sealer, followed by MTA and flowable composite.

Clinical significance: Coronal sealing ability of RMGIC is more promising in comparison with the other agents.

Keywords: Coronal barrier, Enterococcus faecalis, Flowable composite, Microleakage.

How to cite this article: Rashmi N, Shinde SV, MoizAA, Vyas T, Shaik JA, Guram G. Evaluation of Mineral Trioxide Aggregate, Resin-modified Glass lonomer Cements, and Composite as a Coronal Barrier: An in vitro Microbiological Study. J Contemp Dent Pract 2018;19(3):292-295.

Source of support: Nil

Conflict of interest: None

\section{INTRODUCTION}

Success in root canal therapy depends on thorough debridement, cleaning and shaping, and three-dimensional obturation of root canal space, with a hermetic seal at the apex and at the coronal orifice as well. Coronal leakage is one of the factors for the failure of root canal-treated teeth. ${ }^{1,2}$ Obturated root canals may be contaminated by leakage through fractured or dislodged temporary/ permanent restorative material. If the restoration fails to provide a complete seal, it leads to the growth of microorganisms, with $E$. faecalis being the most common one. It is essential to prevent coronal leakage during and after root canal therapy. ${ }^{3}$

Mineral trioxide aggregate has become significantly popular over the past decade because of its enhanced physical and endodontic characteristics. At the same time, an approximate amount of popularity is associated with resin composites and glass ionomer cements (RMGICs) because of their esthetic features. Flowable composites 
are modified conventional composites with reduced filler loading for improvement of the viscosity of these materials. Quantitative microleakage tests have been routinely employed in the past literature for the assessment of microleakage of various endodontic materials without destruction of the experimental specimens. ${ }^{1-3}$

Therefore, the aim of this study was to evaluate MTA, RMGIC, and flowable composite as a coronal barrier against $E$. faecalis.

\section{MATERIALS AND METHODS}

A total of 100 extracted single-rooted human teeth which were noncarious, anatomically normal with mature apex were selected. Teeth were stored in $0.2 \%$ thymol solution immediately after the extraction to keep it moist. Access opening was done using a high-speed handpiece and a \#2 round bur. Working length was established by measuring the length at which the \#15 file was first visible at the apical foramen and subtracting $1 \mathrm{~mm}$ (Figs 1A and B).

Canals were cleaned and shaped using ProTaper files till $\mathrm{f} 3$, in a crown-down fashion with $3 \%$ sodium hypochlorite and saline as the irrigants (Fig. 1C). Canals were dried and obturated with AH-26 sealer and GP using lateral condensation technique. A $3 \mathrm{~mm}$ of GP was removed from the orifice with a heated plugger and depth verified using periodontal probe.

Coronal orifice of each experimental specimen was covered to a depth of $3 \mathrm{~mm}$ with one the test materials.

Teeth were divided into three experimental and two control groups with 20 samples each.

- Group I: MTA (proroot MTA, Dentsply)

- Group II: RMGIC (GC Fuji11LC)

- Group III: Flowable composite (Pulpdent)

- Group IV: Positive control (obturated and without a coronal barrier)

- Group V: Negative control (obturated and completely covered with epoxy resin).

\section{Microleakage Test}

Glass tubes containing BHI broth and equipped with microcaps were the apparatus used to check microleakage. A hole was made at the center of each cap and the tooth was suspended into the glass tube to the level, such that the apical $3 \mathrm{~mm}$ of root is immersed in BHI broth (Fig. 1D). The gap between the tooth and hole was sealed using sticky wax, and the completed apparatus was sterilized by autoclaving. A 24-hour broth culture of E. faecalis was added through the opening of the syringe into the pulp chamber. Samples were incubated at $37^{\circ} \mathrm{C}$ until the BHI broth turned turbid. Fresh 24-hour cultures of E. faecalis were added every 2 days through the study. Turbidity of the broth was monitored daily for 90 days.
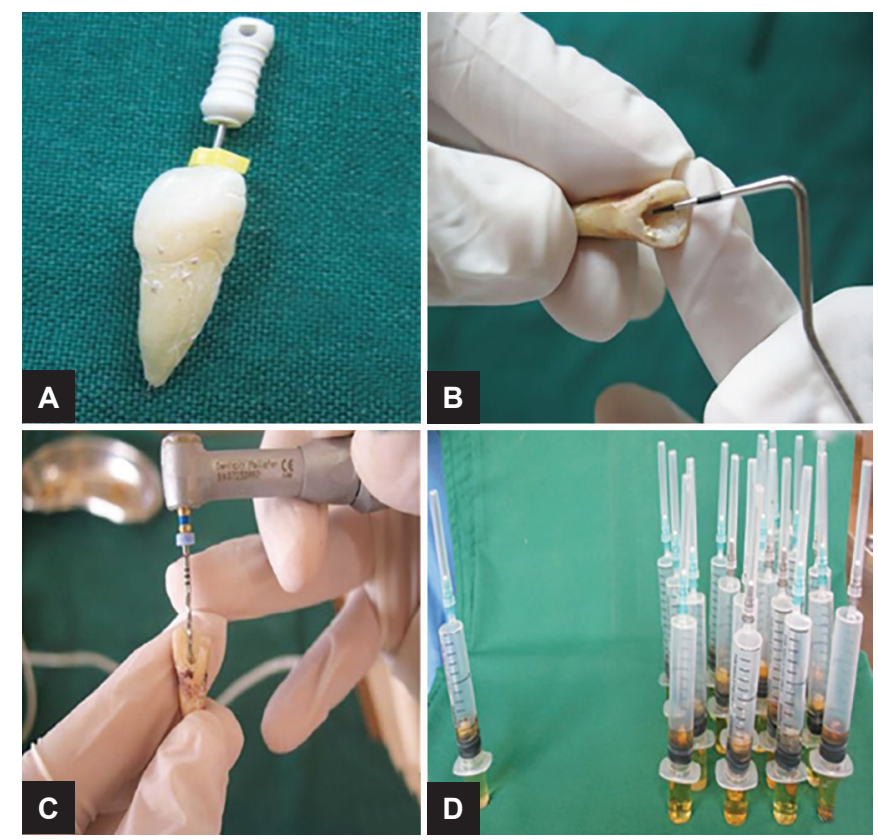

Figs 1A to D: (A) Working length estimation; (B) straight line access by probe; (C) biomechanical preparation; and (D) glass tubes equipped with microcaps apparatus

The data were analyzed using the chi-squared test between the control and experimental groups and Fisher's exact test between the experimental groups.

\section{RESULTS}

The number of samples that turned turbid was significantly lesser in group II followed by group I, and maximum number of samples turned turbid in group III. Chi-squared test was applied and the probability value was found to be $<0.001$, indicating that the difference between the test groups and control groups is statistically significant. When only the test groups were considered, it was seen that the variability of the materials was not statistically significant, with a probability value of 4.560 .

\section{DISCUSSION}

Success of root canal treatment depends on various anatomical and clinical parameters. There are few cases in which the treatment has followed the highest standards and yet resulted in failure. The cause may be due to persistent intra and extraradicular infections. Coronal leakage is one such extraradicular nonmicrobial factor. ${ }^{1-3}$

There are some situations in which obturated root canals may be contaminated due to leakage through the fractured or lost temporary or permanent restoration. Once the coronal seal is lost, microorganisms and their products jeopardize the outcome of the root canal treatment. ${ }^{4,5}$

The purpose of this study was to evaluate the sealing ability of MTA, RMGIC, and flowable composite as a coronal barrier against $E$. faecalis. 
In the present study, 100 extracted human singlerooted teeth were endodontically treated, and $3 \mathrm{~mm}$ of intracoronal GP was removed from the cement-enamel junction and replaced with a test material. The suggested $3 \mathrm{~mm}$ removal of the GP offers enough bulk of the material to provide good seal. Coronal $3 \mathrm{~mm}$ is an ideal cavity, which is surrounded by intact tooth structure, relatively easy to remove during retreatment, and will not limit the thickness of the final restoration. ${ }^{6}$

Microleakage was assessed by a bacterial marker. The culture medium turning turbid was the indication of root canal contamination. Various techniques have been used to assess marginal leakage, such as dyes, ink, radiolabeled ions, bacterial markers, air under pressure, and variations in temperature. Bacterial method was considered over these methods as it is one of the simplest, reliable, and simulates the clinical condition.

The results of the present study showed that all the samples in the positive control group, where no coronal barrier was placed, turned turbid demonstrating bacterial growth. This can be considered as a potential for leakage and is in accordance with studies conducted by Saunders et $\mathrm{al}^{4}$ and Carman and Wallace, ${ }^{7}$ who showed that GP and sealer do not provide an adequate barrier to coronal leakage, and hence, a material with a better sealing ability is required to be placed.

Negative control groups showed no microleakage.

The RMGIC is basically composed of glass particles and small quantities of hydroxyethyl methacrylate and photoinitiators. Adhesion is both chemical and micromechanical. In this study, RMGIC demonstrated better sealing ability when compared with MTA and flowable composite. Good sealing is also due to water sorption property of the material resulting in setting expansion. The results are in accordance with the studies conducted

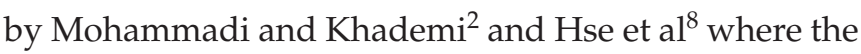
leakage was more in samples of MTA, in comparison with RMGIC. ${ }^{9,10}$

The MTA is a biomaterial consisting of compounds of tricalcium silicate, tricalcium oxide, tricalcium aluminate, and silicate oxide. Setting reaction involves the formation of a hydrated framework by the interlocking of cubic and needle-like crystals, which aided in sealing. ${ }^{11,12}$

In this study, flowable composite showed poor coronal sealing ability when compared with MTA and RMGIC. This is in accordance with the study conducted by Stephens et al, where the MTA samples leaked less than flowable composite. A study conducted by Uranga et al showed that the sealing efficacy of light-cured glass ionomer cement is better than flowable composite. ${ }^{13,14}$

Flowable composites do not contain filler particles as a part of their composition and hence are known to eventually increase polymerization shrinkage and consequently a poor seal; also, there are chances of contraction gap formation after the setting of the material. ${ }^{15-17}$

Intracoronal sealing ability of MTA and RMGI was tested by Barreshi-Nusair and Hammad ${ }^{15}$ in a die leakage study. They observed that the lesser quantity of leakage of die was made up of the RMGIC group. However, the results observed by the authors were statistically nonsignificant and were believed to be due to RMGIC's composition. The RMGIC contains filled adhesives and hence, decreased polymerization shrinkage and gave better sealing ability.

In a study which was conducted by Molander et $\mathrm{al}^{18}$ to test the leakage of RMGIC and flowable composite, there was observed no significant difference between the two, while the leakage was comparably more in flowable composite due to better adhesion in RMGIC is attributed to its composition and leakage to a greater extent in flowable composite was due to polymerization shrinkage. Additional advantage of RMGIC would be that no pretreatment is necessary for its placement.

Kwon and Park, ${ }^{19}$ in another study, assessed whether flowable composites can be applied as pit and fissure sealants without using bonding agents or not. They used three flowable composites (Filtek Flow, Tetric Flow, Charmfil Flow) along with a filled sealant. They used scanning electron microscope for comparing the pattern of resin tag formation in all the sealant materials. They used 54 freshly extracted human premolars and divided them randomly into three study groups with one out of the three flowable composites in each group applied to occlusal fissures. On assessing the microleakage in the three study groups, they observed that all the three flowable composites exhibited similar levels of microleakage. They concluded that in the mechanical sealing of occlusal fissures, filled sealant was more effective.

\section{CONCLUSION}

Within the limitations of the study, it can be concluded that RMGIC is a better coronal sealer, followed by MTA and flowable composite.

\section{REFERENCES}

1. Ingle, JI.; Bakland, LK. Endodontics. 5th ed. Hamilton (ON): BC Decker; 2002. pp. 571-636.

2. Mohammadi Z, Khademi A. An evaluation of MTA cements as coronal barrier. Iran Endod J 2006 Fall;1(3):106-108.

3. Siqueira JF Jr. Aetiology of root canal treatment failure: why well-treated teeth can fail. Int Endod J 2001 Jan;34(1):1-10.

4. Saunders WP, Saunders EM. Coronal leakage as a cause of failure in root-canal therapy: A review. Endod Dent Traumatol 1994 Jun;10(3):105-108.

5. McComb D, Smith DC. A preliminary scanning electron microscopic study of root canals after endodontic procedures. J Endod 1975 Jul;1(7):238-242. 
6. Taneja S, Kumari M. Effect of internal matrices of hydroxyapatite and calcium sulfate on the sealing ability of mineral trioxide aggregate and light cured glass ionomer cement. J Conserv Dent 2011 Jan;14(1):6-9.

7. Carman JE, Wallace JA. An in vitro comparison of microleakage of restorative materials in the pulp chamber of human molar teeth. J Endod 1994 Dec;20(12):571-575.

8. Hse KM, Leung SK, Wei SH. Resin-ionomer restorative materials for children: a review. Aust Dent J 1999 Mar;44(1): $1-11$.

9. Jacobsen EL, Karras LG, BeGole EA, Daniel JC. Long-term sealing efficacy of four root surface sealing materials used in endodontic leakage studies. J Endod 1993 Dec;19(12): 587-590.

10. Lim KC. Microleakage of intermediate restorative materials. J Endod 1990 Mar;16(3):116-118.

11. Beckham BM, Anderson RW, Morris CF. An evaluation of three materials as barriers to coronal microleakage in endodontically treated teeth. J Endod 1993 Aug;19(8):388-391.

12. Tang HM, Torabinejad M, Kettering JD. Leakage evaluation of root end filling materials using endotoxin. J Endod 2005 Dec;31:605-607.
13. Jenkins S, Kulild J, Williams K, Lyons W, Lee C. Sealing ability of three materials in the orifice of root canal systems obturated with guttapercha. J Endod 2006;32:225-227.

14. Uranga A, Blum JY, Esber S, Parahy E, Prado C. A comparative study of four coronal obturation materials in endodontic treatment. J Endod 1999;25:178-180.

15. Barreshi-Nusair KM, Hammad HM. Intracoronal sealing comparision of mineral trioxide aggregate and glass ionomer. Quintessence Int 2005 Jul-Aug;36(7-8):539-545.

16. Möller AJ, Fabricius L, Dahlén G, Ohman AE, Heyden G. Influence on periapical tissues of indigenous oral bacteria and necrotic pulp tissue in monkeys. Scand J Dent Res 1981 Dec;89(6):475-484.

17. Swanson K, Madison S. An evaluation of coronal microleakage in endodontically treated teeth. Part 1. Time periods. J Endod 1987 Feb;13(2):56-59.

18. Molander A, Reit C, Dahlén G, Kvist T. Microbiological status of root-filled teeth with apical periodontitis. Int Endod J 1998 Jan;31(1):1-7.

19. Kwon HB, Park KT. SEM and microleakage evaluation of 3 flowable composites as sealants without using bonding agents. Pediatr Dent 2006 Jan-Feb;28(1):48-53. 